\title{
Introduction to A Research Agenda for Economic Psychology
}

\section{Katharina Gangl and Erich Kirchler}

\subsection{Introduction}

Economic psychology studies the perception and understanding of economic phenomena, financial decision-making and behaviour, egoistic and altruistic mind-sets and cooperation, emotions and well-being (Van Raaij, 1981). The study of humans' economic mental representations and behaviour can be traced back to Greek philosophers and seventeenth-century economists (Ranyard, 2018). However, the history of psychological engagement in the field started rather late, at the beginning of the twentieth century (Kirchler and Hoelzl, 2018).

In 1902, the term 'economic psychology' was coined by Gabriel Tarde, who published a book in which he criticized classical economic assumptions of humans as rational utility-maximizing agents. In 1912, the applied psychologist Hugo Münsterberg (1912) started to examine research questions related to work, marketing and consumption, such as the impact of advertisement on consumer behaviour or strategies of personnel selection. A classical study in the field examined the aftermath of the Great Recession: in an exemplary study, the social-psychologists and sociologists Marie Jahoda, Paul Felix Lazarsfeld and Hans Zeisel investigated the effect of long-term mass unemployment in a small Austrian village. They developed innovative methods to study the effects of job loss on individuals, families and the community in general. Besides conducting interviews, they invited redundant citizens of the village to keep diaries; analysed in children's drawings the impact of redundancy on the family; to understand use of time they took notes on the walking speed of the jobless, of their partners, and people still occupied; and organized workshops and seminars in the village to understand people's capacities to help themselves and to prevent them from becoming increasingly passive and helpless. The results are reported in the 1933 published book The Unemployed of Marienthal: A Sociographical Attempt to Examine the Effects of Long-term Unemployment, in which the authors conclude that unemployment and particularly long-term unemployment does not lead to social revolt but to helplessness and resignation, especially in the case of financial hardship.

In the 1940s, George Katona started his seminal work on spending behaviour and money management and in 1952 he invented the 'Index of Consumer Sentiment', 
which is still used to assess people's economic expectations and to predict economic developments (Ranyard, 2018). In the 1960s and 1970s, empirical research on economic decision-making flourished, with Herbert Simon - an economist seriously interested in psychology - awarded the Sveriges Riksbank (Bank of Sweden) Prize in Economic Sciences in Memory of Alfred Nobel, the so-called 'Nobel Prize in Economics', 'for his pioneering research into the decision-making process within economic organizations' (Royal Swedish Academy of Sciences, 1978). Daniel Kahneman and Amos Tversky started their famous work on decision heuristics and framing effects around that time and developed the well-known and highly influential 'prospect theory'. The theory describes decisions under uncertainty. When deciding between probabilistic alternatives that involve risk, people first reduce the complexity of the decision-making situation and then they consider the value of possible outcomes and their probabilities. In the process of taking decisions, people use heuristics, are prey to biases and evaluate gains less than losses. Rather than making optimal decisions, situational cues and framing effects can lead to choices that are suboptimal. In 2002, Daniel Kahneman was awarded the Nobel Prize in Economics. The success of economic psychology and behavioural economics continues: in 2017, Richard Thaler was awarded the Nobel Prize in Economics for his pioneering work in behavioural economics, especially for incorporating 'psychologically realistic assumptions into analyses of economic decision-making. By exploring the consequences of limited rationality, social preferences, and lack of self-control, he has shown how these human traits systematically affect individual decisions as well as market outcomes' (Royal Swedish Academy of Sciences, 2017).

Economic psychology as an independent field of research gained momentum with the foundation of the Journal of Economic Psychology in 1981 and the first conference of the International Association for Research in Economic Psychology (IAREP) in 1982. Since that time, the journal has published research in economic psychology and behavioural economics and IAREP organizes annual conferences that are attended by psychologists, economists, sociologists, anthropologists and scholars of related fields. An analysis of published articles in the Journal of Economic Psychology until 2005 revealed that most research topics are related to consumer behaviour and individual (financial) decision-making (Kirchler and Hoelzl, 2006).

Kahneman and Tversky's work inspired economists to include psychological insights in their analyses of economic phenomena. 'Behavioural economics' advanced to become a respected branch of economics. Economic psychology and behavioural economics are closely related (Kirchler and Hoelzl, 2018) and they share the same research topics. Behavioural economics has a broad interdisciplinary theoretical foundation and mostly uses incentivized experimental methods. Compared to that, economic psychology builds on psychological theories and uses a wide range of qualitative and quantitive research methods (Fetchenhauer et al., 2012).

From the beginning, research in economic psychology oscillated between the understanding of human decision-making and the development of applied research 
fields around consumption; money management in households and financial investments on the stock market; labour; entrepreneurship; shadow economics and tax behaviour; and wealth and well-being. Based on its deeply inscribed interdisciplinary nature, economic psychology is able to generate important contributions to research and applications (Ranyard, 2018). Based on an empirical-driven understanding of human perception of economic phenomena, decision-making and behaviour, the field aims to provide insights into consumption habits, financial behaviour, collaboration in society, work and entrepreneurial innovation, that are relevant to citizens, business people and politicians who are interested in regulating behaviour in society not only by using command-and-control strategies but by 'nudging' people to make better choices.

Taking current textbooks as a reference (Kirchler and Hoelzl, 2018; Tomer, 2017) and edited volumes (Altman, 2015, 2017; Leiser and Shemesh, 2018; Lewis, 2017; Ranyard, 2018), contemporary basic and applied economic psychology studies a wide and diverse field of topics. Basic research concerns the underlying dynamics of economic decision-making related to subjective value and risk perceptions, intertemporal choice, mental accounting, decision heuristics, framing effects, and so on. Other basic research questions relate to the development of economic understanding among children, lay theories about economic phenomena, such as money or poverty, and attempts to improve economic understanding and decisionmaking through choice architecture. Also, research on individual well-being and happiness has a long tradition in economic psychology.

Applied research questions can be categorized into whether they concern consumption, labour or financial management. A strong strand in economic psychology examines consumer perceptions and decisions concerning purchases and consumption, saving, credit use and debts. Research that can be grouped under the heading 'work and labour markets' examines decisions to accept or decline work, entrepreneurship or unemployment. Financial decisions are related to investing in the stock market, saving, tax behaviour, gambling or donations.

The present book collects state-of-the-art reviews on classical and novel research fields in economic psychology. The selection of research topics addresses some of the relevant current challenges in our society such as over-indebtedness, digitalization, environmental pollution, unemployment, gender and the workplace, unethical conduct in organizations or tax evasion. To increase the diversity of presented research approaches, we invited experts as well as young researchers from different countries to summarize their research and to outline promising future research steps. Following our research tradition, the contributors' backgrounds are equally based in psychology and economics. Although the focus of the current book is on applied research, important contributions to basic research are also made and the authors were invited to identify important challenges and trends of empirical research. In the following, we summarize each of the chapters. 


\subsection{Summary of chapters}

In Chapter 2 by Agata Gasiorowska, 'Lay people's and children's theories of money', the literature on the psychological functioning of money is reviewed. Economists consider the instrumental value of money as means of economic exchange. However, for many individuals, money also has a symbolic meaning that influences their purchase and saving decisions. For instance, money can have a value in itself, such that individuals accumulate much more money than would be necessary to satisfy their needs. Psychological research also shows that money has no absolute but a relative value. Individuals ascribe different values to money depending on whether they are at the end of the month when their salary is almost spent or at the beginning of the month; on which 'account' the money is mentally stored (e.g., mental account for leisure activities, for housing or food); or depending on how the money was acquired (e.g., hard work versus windfall gain). Research on priming shows that money can also change a situation such that more agency and individualism is triggered in individuals. However, individuals differ in their tendency to see money in instrumental versus symbolic terms. The chapter concludes that future research should analyse how cultural background and different childhood experiences contribute to the development of instrumental and symbolic meaning of money. Whereas several studies show that the instrumental value develops at specific developmental stages, relatively little is known on how the symbolic meaning of money evolves in children.

In Chapter 3 by Krishane Patel and Ivo Vlaev on 'Improving financial capability', a model on financial capability is presented. Based on that, a framework to improve financial capability is outlined. Based on a literature review, the authors present a model of behavioural financial capability, suggesting that it is the interaction between abilities, motivations and opportunities that counts. Abilities are composed of psychological capabilities (e.g., knowledge, comprehension) and physical capabilities (e.g., skills, physical ability). Motivation includes reflective processes such as evaluation, goal-setting and planning, and automatic processes, which are based on habits, heuristics and biases. Opportunities can be social, related to the cultural milieu, or physical, based on infrastructure and technology. Based on this model, the authors apply a behavioural change framework deriving from health care research to outline how financial capability can be improved. It is suggested that, first, a formative understanding of the problematic behaviour is necessary (e.g., through observation). Second, the behaviour needs to be modelled to provide diagnostics and to identify key parameters and barriers. In a third step, building of interventions follows by utilizing behavioural change techniques such as reminders. Finally, long-term behaviour change is aspired to through habit formation based on the repetition of behaviour constrained by time, location, preceding and subsequent action and psychological state. The authors state that future research should contribute to adequately understanding the processes behind behavioural change based on insights from big data and neuronal network analyses (e.g., consumer banking activities). 
Chapter 4 by Jashim Khan and Gary Rivers, 'Role of "owned" money and rational spending', empirically investigates how payment modes influence spending behaviour. Numerous studies suggest that card payments lead to more spending than cash payments. However, the underlying psychological processes are still not thoroughly understood. The chapter reviews the current literature and discusses the role of experienced pain when spending money, payment transparency, perceived ownership and tangibility of payment mode. It is hypothesized that cash enables more sensory perceptions than card payments that trigger more cognitive and emotional associations and stimulate a higher sense of ownership. Positive emotions that are associated with the ownership of cash money encourage the possessor to extend the duration of possession, thus to reduce unnecessary spending. To test these assumptions, a survey study including 385 individuals recruited at the entrance to a grocery retailer was conducted. Survey data of participants was matched to the receipts from their grocery shopping. Results show that positive emotions towards payment mode (cash or card) were only indirectly related to grocery spending via the mediators social gratification and money management. In addition, for positive emotions towards cash payment this mediation was moderated by felt ownership. For positive emotions towards card payment the mediation was moderated by felt awareness of spending. The chapter concludes that payment modes influence spending behaviour because of different related emotions and cognitions such social gratification or felt ownership related with various payment modes. The chapter ends by suggesting that research is needed that considers the influence of various purchase and cultural contexts on the effects of payment modes. Finally, the effect of new payment modes such as mobile devices or block-chain money also need further examination.

Chapter 5 by Cäzilia Loibl is about 'Debts and over-indebtedness of private households'. Over-indebtedness affects health, work productivity and family relationships. The chapter first summarizes the different approaches to examining indebtedness. The financial approach focuses on numbers in balance sheets and cash flow statements based on data that are provided by government agencies, credit reporting agencies, banks or credit counselling agencies. Psychological research assesses the individuals' perceived debt burden and its determinants such as socio-demographic characteristics or debt attitudes. Social approaches discuss how debts affect families and how family networks can help to manage debts. Health approaches analyse debt as a financial stressor that affects physical health, measured by survey questions and recently by biomarkers (e.g., for diabetes). The fact that many countries regularly conduct nationwide surveys and assess indebtedness from these different perspectives offers a great opportunity for researchers. The chapter also discusses the main contributors to indebtedness such as mortgage debt, student loans, credit card borrowing and car loans. Future research should focus on the increasing number of indebted retired people and their financial decisions regarding housing or health care. Also, gender effects of indebted individuals on life decisions such as marriage or having children are relevant future research avenues. Little is also known about the effect of experiencing economic turmoil such as recession on the debt attitudes. Finally, more research on how consumers 
monitor their expenses, on the effectiveness of financial interventions such as debt advisory tools and services are suggested.

Chapter 6 by Sarah Diefenbach and Marc Hassenzahl, 'Psychology in product design' reviews the literature and examples on designing new products for the contemporary (digital) market. In the past, products were based on solid consumption and endowment and the design of products and services tried to increase the optimal fit between product qualities and human cognitive abilities. However, today most products are combinations of material artefacts and immaterial services, which leads to a considerable change in consumption. Today's liquid consumption is ephemeral, access based and immaterial and emphasizes practices, experiences and networks rather than object attachment. Thus, modern product design has a human-centred experience perspective and understands the experiential value of a product as an important factor of business success. Usability design is replaced by experience design. Experience may even replace quality as the main battleground. The chapter argues that psychology, particularly marketing and economic psychology, can offer important insights for designing these new products. The reason is that new product design needs to increase interaction and social connectedness, that technical functionality is replaced by users' subjective experience and that the design of experiences becomes the core of business success. However, methods need to be improved in order to appropriately address experiences and prolonged use related to a continuous relationship between consumers and products. Time-intense longitudinal field studies are not feasible in the fast-changing environment of today's vendors. Retrospective interview techniques could help to capture change over time without the need for repeated measurement. HomeLabs might be used where individuals test products in a fully equipped home. Design theatres and role-plays can be used to explore and evaluate possible uses for, for example, social robots. Such methods also allow the assessment of behaviour and experiences in speculative situations with new products.

Chapter 7 by Daniel Schwartz, Taciano L. Milfont and Denis Hilton, 'The interplay between intrinsic motivation, financial incentives and nudges in sustainable consumption', summarizes the literature factors shaping the behaviour that promotes positive or averts negative environmental effects. Three factor categories are discussed: intrinsic motivation, financial incentives, and choice architecture (nudging). Individuals with high intrinsic motivation to protect the environment show more environmentally friendly behaviour than individuals with extrinsic or controlled motivation. Intrinsic motivation is related to gender, political orientation, altruistic values and personality traits such as agreeableness. Financial incentives should signal what the desirable behaviour is and should reduce the costs of sustainable consumption. Nudges concern altering the choice environment, reminders of financial benefits, and normative messages. The chapter continues by discussing the interplay between intrinsic motivation, financial incentives and nudges. For instance, research indicates that taxes are more effective in changing behaviour than bonuses if they signal normative opinions. Financial incentives can crowd out intrinsic motivation and reduce attention to environmental benefits. However, among individuals with low intrinsic motivation, incentives can increase 
pro-environmental behaviour. Future research on sustainable consumption needs more methodological rigour. More field studies with real incentives instead of scenario studies are needed. More research is also needed on the processes that influence behaviour, on the impact of combined applications of incentives and nudges, and on targeted strategies for specific consumer groups.

Chapter 8 by Jan M. Bauer and Lucia A. Reisch on 'Behavioural insights and (un)healthy dietary choices: A research agenda for better evidence', reviews the literature on behavioural interventions to improve healthy lifestyles. Increasing obesity rates and its related health problems and costs for society become an urgent problem. However, in contrast to alcohol abuse, governments cannot legally forbid eating unhealthy food. Also, providing information has no effect as individuals know that they eat unhealthily, but still are not able to resist the offers of snacks and other unhealthy food and advertisement temptations. Therefore, behavioural intervention based on choice architecture seems to be a promising approach to solving the problem. The chapter discusses six strategies for future research that could help to design effective nudges. First, tools should be tested in the real world and specific settings and results should be shared with others to determine 'what works'. Second, coherent terminology and design procedures need to be established, and generally, coordination of research activities needs to be increased. Third, more research on long-term effects and habit formation is needed. Fourth, potential (negative) side-effects of nudges should be considered in future research. Fifth, research on more heterogeneous samples and in culturally diverse countries is needed. Sixth, scalability of effects found in the laboratory to the real world needs to be considered.

Chapter 9 by Diana Stimmler and Carmen Tanner, 'Preventing wrongdoing and promoting ethical conduct: A regulatory focus approach to corporate ethical culture', reviews the literature on ethical business cultures. Ethical business cultures are composed of compliance and integrity approaches. A compliance approach seeks to reduce unethical conduct in the organization by preventing unethical conduct through control, monitoring and punishment. In contrast, an integrityoriented approach aims to promote ethical conduct by encouraging self-governance and responsibility. Despite the widely accepted distinction between compliance and integrity, empirical examination is weak. It is not clear whether an integrity approach really adds value to existing compliance approaches. Moreover, research on different psychological and work-related outcomes of compliance and integrity approaches is rare. The chapter emphasizes that it would be particularly promising for future research to investigate the relationship between the compliance and integrity approach and the regulatory focus of individuals (i.e., promotion versus prevention focus). Finally, a set of hypotheses is presented on how compliance and integrity approaches trigger different regulatory foci and therefore different motivations, perceptions, decisions, and behaviours related to ethical business conduct.

Chapter 10 by Clara Kulich and Janine Bosak, 'The persistence of gender inequality leadership: Still a long way to go?' reviews the literature on reasons for gender 
inequality. Despite advances in gender equality, women are still under-represented in many typically masculine work domains. Women also hold fewer leadership positions, receive poorer performance evaluations and earn less than men despite equal qualifications. The chapter outlines possible barriers to gender equality related to gender stereotypes. Gender stereotypes of agentic and dominant men and passive and prosocial women lead to a perceived incongruity between a female gender role and, for instance, a leadership role. Stereotypes in turn lead individuals to punish women who strive for leadership positions because they violate normative gender standards. Also, women themselves are prey to these stereotypes and in turn, reduce their ambitions or downplay their performance in order to fit the traditional gender role. The chapter also reviews barriers that are related to contextual dynamics such as differences between business sectors, discriminatory environments or support among women. Another barrier discussed is that women as leaders are often a strategic choice and appointed during difficult times, which is a hindrance to staying in their leadership positions. Finally, the chapter discusses higher female representation, female role models and a positive climate for gender inclusion as key factors to foster gender equality. Future research needs to analyse the quality and context of female leader appointments to detect possible hidden barriers underlying the visible increase in numbers of female leaders.

Chapter 11 by Barbara Hartl and Eva Hofmann is on the 'Sharing economy'. It reviews consumer activities related to sharing (instead of buying and owning) goods and services. The chapter discusses different definitions of the sharing economy and presents different business models (business-to-consumer, peer-topeer, community sharing) and examples of the sharing economy such as apartment sharing (e.g., Airbnb) or car sharing (e.g., Zipcar). The chapter also reviews determinants that predict individual consumers' participation in the sharing economy such as demographics or motivations and discusses the importance of trust in the relationship-based sharing economy. The chapter proposes that future research should investigate further the role of trust. For instance, depending on the relationship (e.g., between consumers; between consumers and different providers) and whether the sharing is online or not, trust is more or less important, and more or less difficult to establish. Future research should also investigate the dark side of the sharing economy to minimize risks for consumers and sellers. Finally, more research is needed that applies methods that go beyond interview and case studies such as observational and diary studies or field experiments.

Chapter 12 by Maximilian Sommer on 'Basic income: Insights from social experiments and simulations', explains the concept of a basic income as replacement of all social transfers in favour of an unconditional basic income for everyone. A basic income has the aim to reduce poverty, to eliminate governmental paternalism and to increase freedom. Critics argue that a basic income is the abandonment of the subsidiarity principle, will reduce the labour supply and is related to high costs. The chapter discusses challenges of the basic income - for example, that not all social transfers (e.g., support for children, disabled people) can be replaced. Another problem is that a higher basic income reduces the number of taxpayers. 
However, tax earnings need to be large enough to finance the system. The chapter also presents different options (negative income tax versus regular payment) to implement the basic income and reviews the existing examples from Alaska, the USA, Finland, Namibia and Kenya. Also, results from micro-simulations are reported that show that low marginal tax rates can increase labour supply. The chapter ends with a discussion of methodological problems to empirically test the effects of basic income.

Chapter 13 by Katharina Gangl on the 'Status quo and future research avenues of tax psychology', provides a short overview of the history of taxation and the varieties of tax behaviours. The chapter reviews determinants of tax behaviour. Socio-demographic characteristics (e.g., gender, age), economic factors (e.g., audits, fines), psychological factors (e.g., trust, tax knowledge), third-party influence (e.g., tax practitioners, tax havens), and country differences (e.g., tax morale, economic differences) are presented. Also, theoretical models of tax behaviour such as the slippery slope framework are discussed. The chapter proposes that more future research is needed on how the different determinants of tax compliance interact with each other. For instance, psychological factors such as trust and fairness might be important boundary conditions for the effectiveness of economic factors such as audits and fines. The chapter also discusses the potential of new research methods such as big data analyses, machine learning or field experiments that simultaneously assess field data and survey data. Finally, research gaps are discussed that concern the psychological and behavioural effects of digitalization (e.g., the automation of tax collection) and tax compliance in developing countries.

The final chapter, Chapter 14, 'Happiness and economic prosperity' by Olga Stavrova and Simon Asbach, reviews the literature on the question of whether money can buy happiness. Cross-sectional data, longitudinal data and quasi-experiments (for instance, comparisons between East and West Germany) show a significant but small relationship between wealth and happiness. However, research also suggests that in poor societies the relationship between wealth and happiness is stronger than in rich societies. Studies also indicate that relative income is important for happiness. People tend to be happier if their income is higher than the income of similar others. The chapter also discusses possible moderators of the relationship between wealth and happiness such as individual characteristics and the way money is spent. For instance, it seems that spending money on others makes us happier than spending money on ourselves; also, spending money on many things makes us happier than spending money on one large thing. More research is needed to understand when wealth actually decreases happiness. For instance, residents of wealthy nations report a lower meaning in life and have higher depression rates than residents of poor nations. Also, lay beliefs about happiness and their influence on life decisions need further examination as well as the relationship between specific consumption patterns and happiness. 


\section{References}

Altman, M. (ed.) (2015). Real-world Decision Making: An Encyclopedia of Behavioral Economics. Santa Barbara, CA: Greenwood.

Altman, M. (ed.) (2017). Handbook of Behavioural Economics and Smart Decision-making Within the Bounds of Reason. Cheltenham, UK and Northampton, MA, USA: Edward Elgar Publishing.

Fetchenhauer, D., O.H. Azar and G. Antonides et al. (2012). 'Monozygotic twins or unrelated stepchildren? On the relationship between economic psychology and behavioural economics'. Journal of Economic Psychology, 33(3), 695-9.

Jahoda, M., P.F. Lazarsfeld and H. Zeisel (1933). Die Arbeitslosen von Marienthal: Ein soziographischer Versuch über die Wirkungen landandauernder Arbeitslosigkeit [The Unemployed of Marienthal: A Sociographical Attempt to Examine the Effects of Long-term Unemployment]. Leipzig: Hirzel.

Kirchler, E. and E. Hoelzl (2006). 'Twenty-five years of the Journal of Economic Psychology (1981-2005): A report on the development of an interdisciplinary field of research'. Journal of Economic Psychology, 27(6), 793-804.

Kirchler, E. and E. Hoelzl (2018). Economic Psychology: An Introduction. Cambridge, UK: Cambridge University Press.

Leiser, D. and Y.S. Shemesh (2018). How We Misunderstand Economics and Why It Matters: The Psychology of Bias, Distortion and Conspiracy. London: Routledge.

Lewis, A. (ed.) (2017). The Cambridge Handbook of Psychology and Economic Behaviour. Cambridge, UK: Cambridge University Press.

Münsterberg, H. (1912). Psychologie und Wirtschaftsleben: Ein Beitrag zur angewandten ExperimentalPsychologie [Psychology in the Economy: A Contribution of Applied Experimental Psychology]. Leipzig: J.A. Barth.

Ranyard, R. (2018). 'Introduction to economic psychology: The science of economic mental life and behaviour'. In R. Ranyard (ed.), Economic Psychology (pp. 3-18). Singapore: Wiley.

Royal Swedish Academy of Sciences (1978). 'Studies of decision-making lead to prize in economics'. Press release, 16 October. Accessed 20 November 2018 at https://www.nobelprize.org/prizes/ economic-sciences/1978/press-release/.

RoyalSwedishAcademyofSciences(2017).'ThePrizeinEconomicSciences2017-integratingeconomicswith psychology'. Accessed 20 November 2018 at http://news.cision.com/kungl--vetenskapsakademien/r/ the-prize-in-economic-sciences-2017--integrating-economics-with-psychology,c2363261.

Tarde, G. (1902). 'Psychologie économique' [Economic psychology]. Revue de Métaphysique et de Morale, 10(1), 1-2.

Tomer, J.F. (2017). Advanced Introduction to Behavioral Economics. Cheltenham, UK and Northampton, MA, USA: Edward Elgar Publishing.

Van Raaij, W.F. (1981). 'Economic psychology'. Journal of Economic Psychology, 1(1), 1-24. 